\title{
The relationship between intimate partner violence and probable depression among adolescent girls and young women in Lilongwe, Malawi
}

\author{
Savvy K. Brar ${ }^{a, b, c}$, Tara S. H. Beattie ${ }^{d}$, Melanie Abas ${ }^{c}$, Dhrutika Vansia ${ }^{a}$, Twambilile Phangab \\ Bertha Maseko ${ }^{a}$, Linda-Gail Bekker ${ }^{\mathrm{D}}{ }^{\mathrm{e}}$, Audrey E. Pettifor ${ }^{\mathrm{f}}$ and Nora E. Rosenberg ${ }^{\mathrm{a}, \mathrm{g}}$ \\ a UNC Project-Malawi, Lilongwe, Malawi; ${ }^{\mathrm{b}}$ Department of Population Health, London School of Hygiene and Tropical \\ Medicine UK, London, UK; ' CHealth Service and Population Research Department, Institute of Psychiatry, Psychology, \\ and Neuroscience, King's College London, London, UK; ${ }^{d}$ Department of Global Health and Development, London \\ School of Hygiene and Tropical Medicine, London, UK; ' Desmond Tutu HIV Centre, Cape Town, South Africa; \\ fDepartment of Epidemiology, University of North Carolina, Chapel Hill, NC, USA; ${ }^{9}$ Department of Health Behavior, \\ University of North Carolina, Chapel Hill, NC, USA
}

\begin{abstract}
This analysis estimates prevalence of intimate partner violence (IPV) and its association with probable depression among adolescent girls and young women (AGYW) in Lilongwe, Malawi, and whether partner's controlling behaviour modifies this relationship. Baseline data was utilised from the Girl Power-Malawi study of 1000 15-24-year-old AGYW in Lilongwe. Emotional, physical, and sexual IPV experiences with a current or recent partner were measured using the modified Conflict Tactics Scale. Probable depression was measured by scoring $\geq 10$ on the Centre for Epidemiologic Studies-Short Depression Scale (CES-D-10). Generalised linear models with log-link and binomial distribution estimated prevalence ratios $(\mathrm{PR})$ and $95 \%$ confidence intervals $(\mathrm{Cl})$ for the association between IPV types and probable depression. Partner's controlling behaviour was examined as an effect modifier. Participants' mean age was 19.2 years, with $70 \%$ never-married. IPV prevalence varied for emotional (59\%), physical (36\%), sexual (46\%), and all forms (20\%). Prevalence of probable depression was $47 \%$. AGYW who experienced each IPV type had a higher prevalence of probable depression: physical (PR:1.54, Cl:1.28-1.86), sexual (1.46, Cl:1.21-1.75), emotional (1.37, $\mathrm{Cl}: 1.14-1.64)$, all forms (1.72, Cl:1.41-2.09). IPV and probable depression were prevalent and strongly associated, especially among AGYW reporting controlling behaviour. Interventions addressing IPV and controlling behaviour may positively impact depression among AGYW.
\end{abstract}

\section{ARTICLE HISTORY}

Received 31 July 2019

Accepted 20 December 2019

\section{KEYWORDS}

Intimate partner violence; depression; adolescent girls; young women; Malawi

\section{Introduction}

Intimate partner violence (IPV) is a pressing global health and human rights issue that affects a large proportion of women worldwide. It is the most common form of violence against women with an estimated global prevalence of $30 \%$ and a lead contributor to the global burden of disease (WHO, 2013). The World Health Organisation (WHO) defines IPV as 'any behaviour within an intimate relationship causing physical, sexual, or psychological harm’ (WHO, 2013).

Experiences of IPV are largely dependent on context, with adolescent girls and young women (AGYW) aged 15-24 in developing countries facing a high burden of IPV, particularly in sub- 
Saharan Africa (SSA) where prevalence estimates range from $12 \%$ to $80 \%$ (Devries, Mak, GarcíaMoreno, et al., 2013; Durevall \& Lindskog, 2015; Vos et al., 2015; WHO, 2013). In SSA, sociocultural norms of a traditional and patriarchal nature dictate a man and woman's place in society, with AGYW often placed at the bottom of the social ladder due to their gender, younger age, and relative inexperience. Younger women are often financially-dependent on their partners and unable to negotiate unwanted sexual experiences, finding themselves in relationships with men who exert power and control over them economically, socially, and/or sexually (Ellsberg, Jansen, Heise, Watts, \& Garcia-Moreno, 2008).

Controlling behaviour in the context of an intimate relationship stems from gender and relationship power inequities and refers to 'control [over] one's partner and decision-making authority', which directly impacts a partner's sense of autonomy (Volpe, Hardie, \& Cerulli, 2012). Violence and controlling behaviour often co-occur, and where one form of IPV exists, others often coexist (Garcia-Moreno, Jansen, Ellsberg, Heise, \& Watts, 2006; Katerndahl, Burge, Ferrer, Becho, \& Wood, 2010). In fact, the absence or presence of controlling behaviour may differentiate occasional 'situational couple violence' - where conflict may escalate and perhaps lead to violence but without any control tactics - from 'intimate terrorism' - where more severe and systematic violence may be used as a form of control (Krantz \& Vung, 2009). The latter circumstances may leave AGYW feeling disempowered and helpless, with lack of agency and ultimately increased risk of depression. Thus it is important to understand whether partner's controlling behaviour may modify the relationship between IPV and depression (Bazargan-Hejazi, Medeiros, Mohammadi, Lin, \& Dalal, 2013).

Globally, the prevalence of depression is $4.4 \%$, with exposure to stressful life events, such as IPV, being a major risk factor (Kim et al., 2015; WHO, 2016). In SSA, prevalence estimates for depression are considerably higher among women who have experienced IPV compared to those who have not and range from $35.7 \%$ to $63 \%$ (Dillon, Hussain, Loxton, \& Rahman, 2013; Ellsberg et al., 2008; Kim et al., 2015; Mokdad, 2013; WHO, 2016). These studies, however, have rarely included populations of AGYW. Though evidence exists that AGYW are at higher risk for both IPV and depression in lowand middle-income countries, there is limited research in SSA exploring such an association among this specific population (Devries, Mak, Bacchus, et al., 2013; Jewkes et al., 2014; Tsai, 2013; Volpe, Hardie, \& Cerulli, 2012; White \& Satyen, 2015). Since adolescence is a unique developmental stage with potentially different types of sexual behaviour and partnerships, there is a need to better understand whether the relationship between IPV and depression among AGYW differs from that of their older female counterparts.

One of the few examples of such research is Stepping Stones, a study conducted in South Africa, whose evaluation found that young women who experienced IPV, especially concomitant emotional and physical and/or sexual violence, had much higher levels of depression (Jina et al., 2012; Nduna, Jewkes, Dunkle, Shai, \& Colman, 2010). Since the relationship and socioeconomic conditions of South Africa are different from Malawi, it is important to understand a similar question, as examined in the evaluation of Stepping Stones intervention, but in another setting.

This present research seeks to understand the relationship between IPV and probable depression among AGYW, aged 15-24 years, living in Lilongwe, Malawi. We seek to address two specific aims. First, we explore the relationships between emotional, physical, and sexual IPV with probable depression - both isolated and concomitantly. Next, we explore whether having a controlling intimate partner modifies these relationships.

\section{Methods}

\section{Study design, setting, and population}

The Girl Power study was conducted in Lilongwe, Malawi, and Cape Town, South Africa, and was designed to evaluate four different service delivery models for AGYW (Rosenberg et al., 2018). In 
each country, four comparable clinics were selected and randomly allocated to one of four study arms. Individuals were eligible to participate if they were female, aged 15-24, resided in the clinic's catchment area, and were willing to provide locator information. At each clinic, 250 AGYW were recruited, enrolled, and assessed at baseline, 6-months, and 12-months after study enrolment. Sexually-active AGYW were purposively recruited. A detailed description of the study methodology and primary results has been published previously (Price et al., 2018; Rosenberg et al., 2017). For the current study, we conducted a cross-sectional analysis of baseline behavioural survey data collected from 1000 AGYW at the four Malawian clinics.

\section{Data collection and management}

Enrolment was conducted from February to August 2016. A baseline behavioural survey was administered to all study participants at the four health centres at time of enrolment in private locations. The behavioural survey was a structured interviewer-administered questionnaire typically lasting 1$1.5 \mathrm{~h}$. Trained female research officers, aged 20-24, conducted the interviews in Chichewa and recorded participant responses on electronic tablets using Open Data Kit software, which were password protected and encrypted to ensure participant safety.

\section{Outcome assessment}

The outcome of interest, probable depression, was obtained from the ten-item Centre for Epidemiologic Studies Short Depression Scale (CES-D-10) - shorter version of the longer scale (Radloff, 1977). The CES-D-10 measures the frequency of self-reported depressive symptoms over the past week, with items addressing depressed mood, fatigue, reduced concentration, loneliness, and insomnia/ sleep disturbance. Responses are recorded using a 4-point Likert scale ranging from 0 ('rarely or none of the time') to 3 ('all of the time'), with two questions requiring reverse coding as they measure positive mood. Individual item scores were summed to generate a composite CES-D-10 score, ranging from 0 to 30 . This score was dichotomised using the recommended cut-off of $\geq 10$ to indicate probable depression (Radloff, 1977).

\section{Exposure assessment}

IPV was the primary exposure of interest and, in this study, was assessed through different experiences with a current or most recent male intimate partner. IPV and controlling behaviour were both measured using a validated 17-item scale, based on the modified Conflict Tactics Scale (BazarganHejazi et al., 2013; Kishor, 2005). The scale consisted of 12 binary-response items related to ever experiencing specific acts of emotional (4 items), physical (6 items), and sexual violence (2 items) with a current or most recent partner. A participant was considered to experience one of these three IPV types if she had an affirmative answer to at least one item.

Additionally, there were 5 items related to partner's controlling behaviour. The specific questions related to controlling behaviour measured whether a current or recent partner engaged in the following type of behaviour: (1) insisted on knowing where she was, (2) limited contact with her family, (3) limited contact with her friends, (4) accusations of being unfaithful, and (5) jealousy or anger if she talked to other men.

Following guidelines surrounding the measurement of concomitant violence, in our analysis, we assessed the prevalence of emotional, physical, and sexual violence separately, as well as all three types of concomitant violence (Durevall \& Lindskog, 2015). Each IPV experience was compared to a 'clean' reference group consisting of participants reporting no emotional, physical, or sexual violence, as considered best practice after use in a large-scale, multi-country study (Durevall \& Lindskog, 2015). Controlling behaviour was highly prevalent in this population and had considerable 
overlap with experiences of IPV. For the purposes of these analyses, we considered it as a potential effect modifier.

\section{Statistical analysis}

All analyses were conducted using Stata SE 12.0. Observations with missing exposure or outcome data were dropped from the dataset; however, for all variables, missing data did not exceed 5\%. Cross-tabulations were performed for probable depression and different IPV types. Chi-squared tests were conducted to calculate $p$-values and assess the strength of an association between exposure and outcome variables with covariates. Generalised linear models (GLM) with a log-link and binomial distribution were used to model the association of each IPV exposure variable with probable depression, adjusting for confounding effects. Results were reported as prevalence ratios (PR) with $95 \%$ confidence intervals (CI).

Based on the literature, we developed a conceptual framework describing potential confounding pathways between IPV and probable depression and used this to guide our analyses (Figure 1). The final, fully-adjusted model controlled for variables independently associated with both probable depression and IPV - age group, marital status, and asset index (Table 1). Age group was included a priori in all models. Controlling behaviour was examined as a potential effect modifier of these relationships and was included in the models as an interaction term (Lovestad, Love, Vaez, \& Krantz, 2017).

\section{Ethical approval}

Ethics approval for primary data collection was granted by the National Health Sciences Research Committee of Malawi (Reference 15/7/1447) and University of North Carolina, Chapel Hill, Biomedical Institutional Review Board (Reference 15-2901). Permission to conduct secondary data analysis was granted by the London School of Hygiene and Tropical Medicine MSc Research Ethics Committee (Reference 14116). Written informed consent was obtained prior to study participation, with consent for AGYW aged 18-24 and assent for those aged 15-17. For the younger age group, written informed consent was also obtained from a parent, guardian, or authorised community representative.

1 Age, socioeconomic status, maternal orphanhood, schooling, employment, marital status, financial dependence

2. Age at sexual debut, forced sex initiation, transactional sex, young motherhood, unwanted pregnancy, partner's controlling behavior

3. Emotional, physical and sexual violence

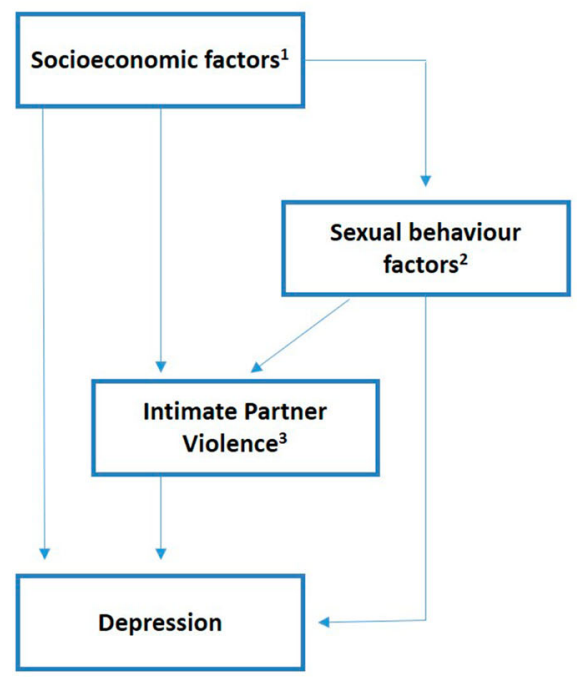

Figure 1. A conceptual framework for the risk factors of intimate partner violence and probable depression among 15-24-year-old adolescent girls and young women in Lilongwe, Malawi. 
Table 1. Baseline characteristics of adolescent girls and young women in Lilongwe, Malawi, by probable depression status, $N=995$.

\begin{tabular}{|c|c|c|c|c|c|c|c|}
\hline \multirow[b]{3}{*}{ Characteristic } & \multirow{2}{*}{\multicolumn{2}{|c|}{$\begin{array}{c}\text { All AGYW }(N= \\
995)\end{array}$}} & \multicolumn{4}{|c|}{ Probable depression } & \multirow[b]{3}{*}{$p$} \\
\hline & & & \multicolumn{2}{|c|}{ No $(N=524)$} & \multicolumn{2}{|c|}{ Yes $(N=471)$} & \\
\hline & $n$ & $(\%)^{\dagger}$ & $n$ & $(\%)^{\dagger}$ & $n$ & $(\%)^{\dagger}$ & \\
\hline \multicolumn{8}{|l|}{ SOCIODEMOGRAPHIC FACTORS } \\
\hline \multicolumn{8}{|l|}{ Age group (years) } \\
\hline $15-19$ & 567 & $(57 \%)$ & 309 & $(60 \%)$ & 258 & $(55 \%)$ & 0.2 \\
\hline $20-24$ & 421 & $(43 \%)$ & 210 & $(40 \%)$ & 211 & $(45 \%)$ & \\
\hline \multicolumn{8}{|l|}{ Marital status } \\
\hline Never married & 694 & $(71 \%)$ & 367 & $(71 \%)$ & 327 & $(70 \%)$ & 0.04 \\
\hline Married or living together & 221 & $(22 \%)$ & 123 & $(24 \%)$ & 98 & $(21 \%)$ & \\
\hline Divorced/separated/widowed & 70 & $(7 \%)$ & 27 & $(5 \%)$ & 43 & $(9 \%)$ & \\
\hline \multicolumn{8}{|l|}{ Asset Index } \\
\hline Low (0-3) & 431 & $(44 \%)$ & 214 & $(41 \%)$ & 217 & $(46 \%)$ & 0.04 \\
\hline Middle (4-6) & 257 & $(26 \%)$ & 129 & $(25 \%)$ & 128 & $(27 \%)$ & \\
\hline High $(>6)$ & 300 & $(30 \%)$ & 176 & $(34 \%)$ & 124 & $(26 \%)$ & \\
\hline \multicolumn{8}{|l|}{ Maternal orphanhood } \\
\hline No & 844 & $(86 \%)$ & 455 & $(88 \%)$ & 389 & $(83 \%)$ & 0.04 \\
\hline Yes & 143 & $(14 \%)$ & 64 & $(12 \%)$ & 79 & $(17 \%)$ & \\
\hline \multicolumn{8}{|l|}{ Primary school } \\
\hline Incomplete & 310 & $(32 \%)$ & 158 & $(31 \%)$ & 152 & $(33 \%)$ & 0.4 \\
\hline Complete & 672 & $(68 \%)$ & 360 & $(69 \%)$ & 312 & $(67 \%)$ & \\
\hline \multicolumn{8}{|c|}{ SEXUAL AND REPRODUCTIVE HEALTH FACTORS } \\
\hline \multicolumn{8}{|l|}{ Age at sexual debut } \\
\hline$<15$ years & 177 & $(18 \%)$ & 80 & $(15 \%)$ & 97 & $(21 \%)$ & 0.03 \\
\hline$\geq 15$ years & 805 & $(82 \%)$ & 436 & $(85 \%)$ & 369 & $(79 \%)$ & \\
\hline \multicolumn{8}{|l|}{ Forced first sex } \\
\hline No & 539 & $(55 \%)$ & 317 & $(62 \%)$ & 222 & $(47 \%)$ & $<0.0001$ \\
\hline Yes & 444 & $(45 \%)$ & 198 & $(38 \%)$ & 246 & $(53 \%)$ & \\
\hline \multicolumn{8}{|l|}{ Transactional sex } \\
\hline No & 755 & $(78 \%)$ & 403 & $(79 \%)$ & 352 & $(77 \%)$ & 0.3 \\
\hline Yes & 213 & $(22 \%)$ & 106 & $(21 \%)$ & 107 & $(23 \%)$ & \\
\hline \multicolumn{8}{|l|}{ Pregnancy history } \\
\hline No & 561 & $(57 \%)$ & 305 & $(59 \%)$ & 256 & $(55 \%)$ & 0.2 \\
\hline Yes & 423 & $(43 \%)$ & 213 & $(41 \%)$ & 210 & $(45 \%)$ & \\
\hline \multicolumn{8}{|l|}{ INTIMATE PARTNER VIOLENCE } \\
\hline \multicolumn{8}{|l|}{ Emotional violence } \\
\hline No & 408 & $(41 \%)$ & 241 & $(46 \%)$ & 167 & $(36 \%)$ & 0.001 \\
\hline Yes & 580 & $(59 \%)$ & 278 & $(54 \%)$ & 302 & $(64 \%)$ & \\
\hline Physical violence & & & & & & & \\
\hline No & 632 & $(64 \%)$ & 370 & $(71 \%)$ & 262 & $(56 \%)$ & $<0.0001$ \\
\hline Yes & 356 & $(36 \%)$ & 149 & $(29 \%)$ & 207 & $(44 \%)$ & \\
\hline Sexual violence & & & & & & & \\
\hline No & 534 & $(54 \%)$ & 316 & $(61 \%)$ & 218 & $(46 \%)$ & $<0.0001$ \\
\hline Yes & 454 & $(46 \%)$ & 203 & (39\%) & 251 & $(54 \%)$ & \\
\hline Any violence & & & & & & & \\
\hline No & 247 & $(25 \%)$ & 155 & $(30 \%)$ & 92 & $(20 \%)$ & $<0.0001$ \\
\hline Yes & 741 & (75\%) & 364 & $(70 \%)$ & 377 & $(80 \%)$ & \\
\hline All violence & & & & & & & \\
\hline No & 792 & $(80 \%)$ & 451 & $(87 \%)$ & 341 & $(73 \%)$ & $<0.0001$ \\
\hline Yes & 196 & $(20 \%)$ & 68 & $(13 \%)$ & 128 & $(27 \%)$ & \\
\hline Controlling behaviour & & & & & & & \\
\hline No & 209 & $(21 \%)$ & 118 & $(23 \%)$ & 91 & $(19 \%)$ & 0.2 \\
\hline Yes & 778 & (79\%) & 401 & (77\%) & 377 & (81\%) & \\
\hline
\end{tabular}

${ }^{\dagger}$ Percentages might not add up to 100 due to rounding.

\section{Results}

\section{Study population}

One thousand AGYW participated in Girl Power-Malawi. Five participants had never had a sexual partner at baseline so could not have experienced IPV and were dropped from this analysis, giving a final analytic sample of 995 participants. Baseline cohort characteristics are summarised in Table 1. Mean age in this cohort was 19.2 years (Standard deviation (SD) 2.5). Majority of participants (70\%) 
were never married. Median number of household assets owned was 4 (Interquartile range (IQR) 2, 8). Fourteen percent of participants reported loss of birth mother and $68 \%$ had completed primary school or higher. Mean age at sexual debut was 16.3 years (SD 2.2), with $45 \%$ of individuals reporting forced first sexual encounter.

\section{Probable depression}

Median score on the CES-D-10 was 9 (IQR 6, 12), with a range of 0-26; 25\% of participants received a score $0-5,35 \%$ received a score $6-10,29 \% 11-15,9 \% 16-20$, and $2 \% 21-26$. Based on a CES-D-10 cut-off of $\geq 10$, the prevalence of probable depression was $47 \%$ (95\% CI: 44-51\%). Items most commonly endorsed for depressed mood were the following: I felt that everything I did was an effort and I felt hopeful about the future, the latter of which was reverse-coded with a higher rating indicating a more 'depressed' answer.

\section{IPV}

The Venn diagram in Figure 2 displays the prevalence of IPV (isolated and concomitant). Overall, $75 \%$ of respondents reported any IPV, defined as experiencing at least one type of violence with a recent partner. Majority of participants (59\%) reported emotional violence, 36\% reported physical violence, and $46 \%$ reported sexual violence. Of the overall sample, $46 \%$ reported experiencing 2 or more types of IPV. The most prevalent IPV combinations were all three types (20\%), emotional and sexual (18\%), and emotional only (15\%). Experiencing only physical and sexual violence was rare (2\%). Additionally, $79 \%$ of the cohort reported controlling behaviour (Table 1), with a vast majority of women who reported IPV also reporting controlling behaviour (Table 2).

\section{IPV and probable depression}

Emotional, physical, and sexual IPV were all associated with probable depression (Table 1). All IPV forms were associated with increased prevalence of probable depression in unadjusted and adjusted

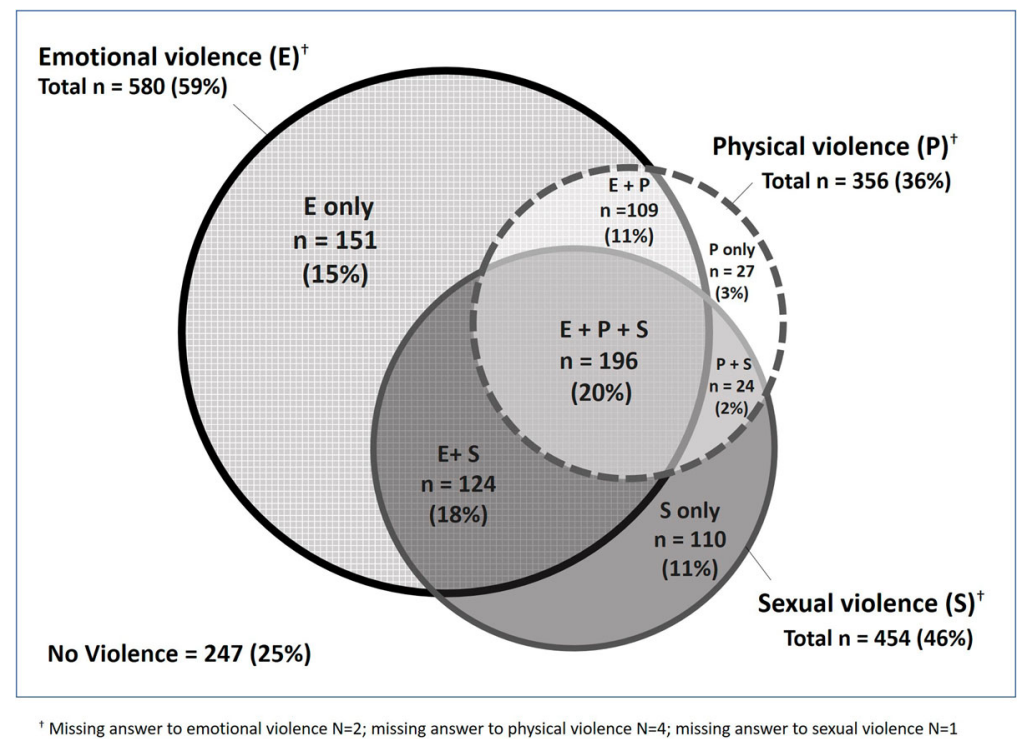

Figure 2. Prevalence of IPV exposure types among 15-24-year-old adolescent girls and young women in Lilongwe, Malawi $(N=$ 988). Notes: *Missing answers to items on emotional violence $(N=2)$, physical violence $(N=4)$, and sexual violence $(N=1)$. 
Table 2. Prevalence ratios (PR) of different IPV types and probable depression among adolescent girls and young women in Lilongwe, Malawi $(N=988)$

\begin{tabular}{|c|c|c|c|c|c|c|c|c|c|c|}
\hline \multirow[b]{2}{*}{ IPV TYPE } & \multirow{2}{*}{$\begin{array}{c}\text { All AGYW, } \\
N(\%)\end{array}$} & \multirow{2}{*}{$\begin{array}{c}\text { AGYW } \\
\text { depressed, } \\
n(\%)\end{array}$} & \multicolumn{4}{|c|}{ UNADJUSTED } & \multicolumn{4}{|c|}{ ADJUSTED* } \\
\hline & & & PR & $(95 \% \mathrm{Cl})$ & $p$ & Interaction $p$ & $\mathrm{aPR}^{*}$ & $(95 \% \mathrm{Cl})^{*}$ & Adjusted $p^{*}$ & Interaction $p^{*}$ \\
\hline No violence [reference group] & 247 & $92(37 \%)$ & \multicolumn{3}{|c|}{ reference group } & - & \multicolumn{3}{|c|}{ reference group } & - \\
\hline No controlling behaviour & 105 & 49 (47\%) & - & - & - & - & - & - & - & - \\
\hline Controlling behaviour & 142 & 43 (30\%) & - & - & - & & - & - & - & \\
\hline Emotional violence & 580 & $302(52 \%)$ & 1.40 & $(1.17,1.67)$ & $<0.0001$ & - & 1.37 & $(1.14,1.64)$ & 0.001 & - \\
\hline No controlling behaviour & 53 & 24 (45\%) & 0.97 & $(0.68,1.39)$ & 0.9 & 0.01 & 0.98 & $(0.68,1.41)$ & 0.9 & 0.02 \\
\hline Controlling behaviour & 526 & 277 (53\%) & 1.74 & $(1.34,2.26)$ & $<0.0001$ & & 1.68 & $(1.29,2.19)$ & $<0.0001$ & \\
\hline Physical violence & 356 & $207(58 \%)$ & 1.56 & $(1.30,1.88)$ & $<0.0001$ & - & 1.54 & $(1.28,1.86)$ & $<0.0001$ & - \\
\hline No controlling behaviour & 19 & 10 (53\%) & 1.13 & $(0.70,1.81)$ & 0.6 & 0.05 & 1.12 & $(0.69,1.79)$ & 0.6 & 0.06 \\
\hline Controlling behaviour & 337 & 197 (58\%) & 1.93 & $(1.48,2.52)$ & $<0.0001$ & & 1.88 & $(1.44,2.46)$ & $<0.0001$ & \\
\hline Sexual violence & 454 & $251(55 \%)$ & 1.48 & $(1.24,1.78)$ & $<0.0001$ & - & 1.46 & $(1.21,1.75)$ & $<0.0001$ & - \\
\hline No controlling behaviour & 81 & 31 (38\%) & 0.82 & $(0.58,1.16)$ & 0.3 & 0.0001 & 0.83 & $(0.59,1.17)$ & 0.3 & 0.0002 \\
\hline Controlling behaviour & 373 & $220(59 \%)$ & 1.95 & $(1.50,2.54)$ & $<0.0001$ & & 1.90 & $(1.45,2.47)$ & $<0.0001$ & \\
\hline Physical OR sexual violence & 590 & $317(54 \%)$ & 1.44 & $(1.21,1.72)$ & $<0.0001$ & - & 1.42 & $(1.19,1.70)$ & $<0.0001$ & - \\
\hline No controlling behaviour & 89 & 35 (39\%) & 0.84 & $(0.61,1.17)$ & 0.3 & 0.0002 & 0.84 & $(0.61,1.17)$ & 0.3 & 0.0004 \\
\hline Controlling behaviour & 501 & $282(56 \%)$ & 1.86 & $(1.43,2.41)$ & $<0.0001$ & & 1.82 & $(1.40,2.36)$ & $<0.0001$ & \\
\hline Any emotional, physical, or sexual violence & 741 & $377(51 \%)$ & 1.37 & $(1.14,1.63)$ & 0.001 & - & 1.34 & $(1.12,1.60)$ & 0.001 & - \\
\hline No controlling behaviour & 104 & $42(40 \%)$ & 0.87 & $(0.63,1.18)$ & 0.4 & 0.0008 & 0.88 & $(0.64,1.20)$ & 0.4 & 0.002 \\
\hline Controlling behaviour & 636 & $334(53 \%)$ & 1.73 & $(1.34,2.25)$ & $<0.0001$ & & 1.68 & $(1.30,2.18)$ & $<0.0001$ & \\
\hline All types of violence (emotional, physical, AND sexual violence) & 196 & $128(65 \%)$ & 1.75 & $(1.45,2.12)$ & $<0.0001$ & - & 1.72 & $(1.41,2.09)$ & $<0.0001$ & - \\
\hline No controlling behaviour & 8 & $5(63 \%)$ & 1.34 & $(0.75,2.38)$ & 0.3 & 0.1 & 1.36 & $(0.76,2.44)$ & 0.3 & 0.2 \\
\hline Controlling behaviour & 188 & $123(65 \%)$ & 2.16 & $(1.65,2.83)$ & $<0.0001$ & & 2.09 & $(1.59,2.76)$ & $<0.0001$ & \\
\hline Physical OR sexual violence ONLY ${ }^{\dagger}$ & 161 & $75(47 \%)$ & 1.25 & $(1.00,1.58)$ & 0.05 & - & 1.25 & $(1.00,1.57)$ & 0.05 & - \\
\hline No controlling behaviour & 51 & $18(35 \%)$ & 0.76 & $(0.49,1.16)$ & 0.2 & 0.002 & 0.79 & $(0.51,1.20)$ & 0.3 & 0.005 \\
\hline Controlling behaviour & 110 & $57(52 \%)$ & 1.71 & $(1.26,2.33)$ & 0.001 & & 1.69 & $(1.24,2.30)$ & 0.001 & \\
\hline
\end{tabular}

Notes: Prevalence Ratio (PR) and 95\% Confidence Interval (95\% Cl).

*Adjusted for age (continuous var), marital status, and asset index (continuous var).

${ }^{\dagger}$ Excludes women exposed to emotional violence. 
analyses (Table 2). Experiencing all three types of IPV was most strongly associated with probable depression (adjusted PR (aPR) 1.72 95\% CI: 1.41-2.09), followed by physical violence (aPR $1.5495 \%$ CI 1.28-1.86), sexual violence (aPR 1.46 95\% CI 1.21-1.75), and physical OR sexual violence (aPR 1.42 95\% CI 1.19-1.70).

When we included controlling behaviour as an effect modifier, we found that among AGYW reporting controlling behaviour, the relationship between violence and probable depression was considerably stronger than among those not reporting controlling behaviour. For those reporting controlling behaviour, the relationships between sexual violence and probable depression (aPR 1.90 95\% CI 1.45-2.47) and physical OR sexual violence and probable depression (aPR 1.82 95\% CI 1.40-2.36) were more than twice as high compared to those reporting no controlling behaviour. In fact, there was no association between any forms of IPV and probable depression among those reporting no controlling behaviour (Table 2). The relationship between physical violence and probable depression was also greater (aPR $1.8895 \%$ CI 1.44-2.46) among those in controlling relationships than those who were not (aPR 1.12 95\% CI 0.69-1.79). These associations held true in both unadjusted and adjusted analyses.

\section{Discussion}

Among an AGYW population aged 15-24 in Lilongwe, Malawi, we observed extremely high levels of both IPV and probable depression. Like previous studies conducted in SSA, there was a high prevalence of probable depression (47\%). IPV was also highly prevalent among this cohort of AGYW, with $46 \%$ reporting experiencing at least 2 types of violence and $20 \%$ experiencing all 3 types. AGYW who experienced each type of violence had a higher prevalence of probable depression, with stronger associations observed among participants also reporting controlling behaviour.

In line with previous research, among this cohort of AGYW, all different types of IPV were positively associated with probable depression in adjusted and unadjusted analysis (Jina et al., 2012; Nduna et al., 2010). The traumatic stress mechanism helps to explain how exposure to IPV may lead to depression (Woollett \& Hatcher, 2016). Through this mechanism, negative experiences like IPV trigger a biological stress response that may alter metabolism and neural functioning. Individuals may experience great psychological distress and be unable to cope, leading to lower selfesteem and self-worth, reduced hope for the future, and resultant depressive symptoms (Kessler, 2003).

This study is unique in its attempt to better understand intimate relationships with very different power differentials through the lens of control tactics. While controlling behaviour was not significantly associated with depression in itself, it was an important modifier of the relationship between IPV and probable depression. AGYW in controlling relationships experienced a strong association between IPV and probable depression, whereas those who were not in controlling relationships did not. These findings could be due to differences in the frequency and severity of IPV experiences, rather than the actual presence of controlling behaviour, differentiating occasional 'situational couple violence' from 'intimate terrorism'.

In Malawi and many SSA contexts, men hold a more dominant position, and violence is often a form of exerting power and control rather than a simple act of aggression (Garcia-Moreno et al., 2006). Many young women view such violent and/or controlling behaviour as an accepted or normal part of relationships (Bazargan-Hejazi et al., 2013; Uthman, Lawoko, \& Moradi, 2010). Experiencing various forms of IPV within the context of these relationships may leave AGYW feeling less empowered in important facets of day-to-day life, from socialising with friends and negotiating sexual experiences to seeking support services for IPV (Tazeen Saeed, Aamir, \& Fazal, 2014). While the present research demonstrates the heightened vulnerability for probable depression among AGYW experiencing IPV in the context of controlling behaviour, an important area for further exploration would be to assess the dimensions of frequency and severity of IPV to gain a better understanding of the dynamics at play. 
While the CES-D-10 has been validated in many southern African contexts, including Malawi among adolescents, with excellent psychometric properties, and has been found to be more easily understood in the SSA context than the Patient Health Questionnaire (PHQ-9), with which it has strong convergent validity, the CES-D-10 is a screening tool for depression rather than a clinical diagnosis tool (Baron, Davies, \& Lund, 2017; Chishinga et al., 2011; Kilburn et al., 2018; Radloff, 1977; White \& Satyen, 2015). As used, it likely provides an over-estimation of the true population prevalence; therefore, it would be valuable to conduct future research among comparable populations of AGYW exploring the use of the CES-D-10 as a screening tool, alongside clinical diagnosis tools for an adequate assessment of depression (Radloff, 1977).

There are several possible sources of information bias, such as social desirability bias. Additionally, response and recall bias could have influenced responses to both the IPV and probable depression questions. Women could have misinterpreted or underreported experiences of IPV due to its private and intimate nature or based on their understanding of questions. Such misreports could lead to issues related to under-reporting, especially for more severe forms of IPV (Garcia-Moreno et al., 2006; White \& Satyen, 2015). However, this is not a major concern given the high reports of both IPV and probable depression. Additionally, the cross-sectional nature of the data precludes the ability to assess temporality and make causal inference. The relationship between IPV and depression could also be bi-directional in that women who are more depressed may find it more difficult to negotiate with partners and thus more willing to endure more violent or unhealthy relationships. However, the parent Girl Power study is a longitudinal, quasi-experimental cohort study that includes social protection interventions that may enable exploration of longitudinal trends.

The main implication of this research is that there is a need to address both IPV and probable depression in this population (which were both highly prevalent), especially among AGYW in controlling relationships, through prevention and treatment efforts. Programmes targeting IPV may have a greater impact on depression among those AGYW in controlling relationships and experiencing 'intimate terrorism'. Additionally, there is a need for better implementation of policy and legislation related to IPV, such as the Gender Equality Act, which was enacted in 2013 and condemns 'sexual harassment and harmful practices', as well as clearer mechanisms for reporting IPV and seeking necessary support (legal, medical, or psychosocial) (Landstedt, Gustafsson, Johansson, \& Hammarstrom, 2016). Additionally, IPV can be prevented directly through greater stakeholder engagement at various levels, as done in the evidence-based SASA!, Stepping Stones, and IMAGE trials (Campbell \& Cornish, 2012). Such interventions increase awareness around IPV, including what it is, what forms it takes, and its legal status in the specific context and address underlying beliefs and attitudes normalising violence and gender inequality. Further community-based and participatory approaches may increase social capital by creating 'safe spaces' for AGYW where they can engage with and support one another for a heightened sense of agency and empowerment, working to reduce the burden and stigma around both IPV and ill mental health in this context (Campbell \& Cornish, 2012).

Considering the high levels of probable depression in this population, it is also necessary to explore low-resource strategies to treat depression among AGYW - irrespective of experience of IPV. One such example is the Friendship Bench Project in Zimbabwe, a task-shifted, stepped-care approach to treat depression, which was delivered through grandmother lay health providers (Abas et al., 2016). A similar approach could be adapted for Malawian AGYW in general, and specifically for those with a history of IPV, it could incorporate a trauma-informed care component, such as that used in the Women's Health Co-Operative or Improving AIDS Care after Trauma (Myers, Carney, Browne, \& Wechsberg, 2018; Sikkema et al., 2018).

In conclusion, these findings provide new information on the association between different experiences of IPV and probable depression among AGYW aged 15-24 years in Lilongwe, Malawi. There have been few studies examining such an association in the SSA context but, given the findings from this research and the substantial burden of depression in this low-resource setting, 
interventions that are guided towards addressing and mitigating the effects of IPV, may also reduce the burden of depression.

\section{Acknowledgements}

All persons who have contributed significantly to the study or manuscript are included in the author list. The authors would like to acknowledge the work of the whole Girl Power team, including the research officers, peer educators, and facilitators, as well as the study participants for sharing their data.

\section{Disclosure statement}

No potential conflict of interest was reported by the author(s).

\section{Funding}

This work was supported by Evidence for HIV Prevention in Southern Africa (EHPSA), a Department of International Development (DFID) programme managed by Mott MacDonald. NER is supported by the National Institutes of Health (R00MH104154) and the National Institute of Allergy and Infectious Diseases (P30 AI50410).

\section{ORCID}

Linda-Gail Bekker (D) http://orcid.org/0000-0002-0755-4386

\section{References}

Abas, M., Bowers, T., Manda, E., Cooper, S., Machando, D., Verhey, R., ... Chibanda, D. J. I. J. o. M. H. S. (2016). 'Opening up the mind': Problem-solving therapy delivered by female lay health workers to improve access to evidence-based care for depression and other common mental disorders through the Friendship Bench Project in Zimbabwe. International Journal of Mental Health Systems, 10(1), 39. doi:10.1186/s13033-016-0071-9

Baron, E. C., Davies, T., \& Lund, C. (2017). Validation of the 10-item centre for epidemiological studies depression scale (CES-D-10) in Zulu, Xhosa and Afrikaans populations in South Africa. BMC Psychiatry, 17(1), 6. doi:10. 1186/s12888-016-1178-X

Bazargan-Hejazi, S., Medeiros, S., Mohammadi, R., Lin, J., \& Dalal, K. (2013). Patterns of intimate partner violence: A study of female victims in Malawi. Journal of Injury and Violence Research, 5(1), 38-50. doi:10.5249/jivr.v5i1.139

Campbell, C., \& Cornish, F. (2012). How can community health programmes build enabling environments for transformative communication? Experiences from India and South Africa. AIDS and Behavior, 16(4), 847-857. doi:10. 1007/s10461-011-9966-2

Chishinga, N., Kinyanda, E., Weiss, H. A., Patel, V., Ayles, H., \& Seedat, S. (2011). Validation of brief screening tools for depressive and alcohol use disorders among TB and HIV patients in primary care in Zambia. BMC Psychiatry, 11(1), 75. doi:10.1186/1471-244x-11-75

Devries, K. M., Mak, J. Y., Bacchus, L. J., Child, J. C., Falder, G., Petzold, M., ... Watts, C. H. (2013). Intimate partner violence and incident depressive symptoms and suicide attempts: A systematic review of longitudinal studies. PLoS Medicine, 10, doi:10.1371/journal.pmed.1001439

Devries, K. M., Mak, J. Y. T., García-Moreno, C., Petzold, M., Child, J. C., Falder, G., ... Watts, C. H. (2013). The global prevalence of intimate partner violence against women. Science, 340(6140), 1527-1528. doi:10.1126/science. 1240937

Dillon, G., Hussain, R., Loxton, D., \& Rahman, S. (2013). Mental and physical health and intimate partner violence against women: A review of the literature. International Journal of Family Medicine. doi:10.1155/2013/313909

Durevall, D., \& Lindskog, A. (2015). Intimate partner violence and HIV in ten sub-Saharan African countries: What do the demographic and health surveys tell us? The Lancet Global Health, 3(1), e34-e43. doi:10.1016/S2214-109X (14)70343-2

Ellsberg, M., Jansen, H. A., Heise, L., Watts, C. H., \& Garcia-Moreno, C. (2008). Intimate partner violence and women's physical and mental health in the WHO multi-country study on women's health and domestic violence: An observational study. Lancet, 371, doi:10.1016/s0140-6736(08)60522-x 
Garcia-Moreno, C., Jansen, H. A., Ellsberg, M., Heise, L., \& Watts, H. C. (2006). Prevalence of intimate partner violence: Findings from the WHO multi-country study on women's health and domestic violence. The Lancet, 368, doi:10.1016/s0140-6736(06)69523-8

Global Burden of Disease Collaborative Network. (2016). Global Burden of Disease Study 2015 (GBD 2015) Risk Factor Results 1990-2015. Seattle, United States: Institute for Health Metrics and Evaluation (IHME).

Jewkes, R., Gibbs, A., Jama-Shai, N., Willan, S., Misselhorn, A., Mushinga, M., ... Skiweyiya, Y. (2014). Stepping stones and creating futures intervention: Shortened interrupted time series evaluation of a behavioural and structural health promotion and violence prevention intervention for young people in informal settlements in Durban, South Africa. BMC Public Health, 14, doi:10.1186/1471-2458-14-1325

Jina, R., Jewkes, R., Hoffman, S., Dunkle, K. L., Nduna, M., \& Shai, N. J. (2012). Adverse mental health outcomes associated with emotional abuse in young rural South African women: A cross-sectional study. Journal of Interpersonal Violence, 27(5), 862-880. doi:10.1177/0886260511423247

Katerndahl, D. A., Burge, S. K., Ferrer, R. L., Becho, J., \& Wood, R. (2010). Complex dynamics in intimate partner violence: A time series study of 16 women. Primary Care Companion To the Journal of Clinical Psychiatry, 12 (4), doi:10.4088/PCC.09m00859whi

Kessler, R. C. (2003). Epidemiology of women and depression. Journal of Affective Disorders, 74, doi:10.1016/s01650327(02)00426-3

Kilburn, K., Prencipe, L., Hjelm, L., Peterman, A., Handa, S., \& Palermo, T. (2018). Examination of performance of the center for epidemiologic studies depression scale short form 10 among African youth in poor, rural households. BMC Psychiatry, 18(1), 201. doi:10.1186/s12888-018-1774-Z

Kim, M. H., Mazenga, A. C., Yu, X., Devandra, A., Nguyen, C., Ahmed, S., ... Sharp, C. (2015). Factors associated with depression among adolescents living with HIV in Malawi. BMC Psychiatry, 15, 264. doi:10.1186/s12888-015-0649-9

Kishor, S. (2005). Domestic violence measurement in the demographic and health surveys: The history and the challenges. Retrieved from Expert paper for UN Division for the Advancement of Women, Geneva, 2005: https:// www.un.org/womenwatch/daw/egm/vaw-stat-2005/docs/expert-papers/Kishor.pdf

Krantz, G., \& Vung, N. D. (2009). 2The role of controlling behaviour in intimate partner violence and its health effects: A population based study from rural Vietnam. BMC Public Health, 9(1), 143. doi:10.1186/1471-2458-9-143

Landstedt, E., Gustafsson, P. E., Johansson, K., \& Hammarstrom, A. (2016). Longitudinal associations between social relationships at age 30 and internalising symptoms at age 42: Findings from the northern Swedish cohort. International Journal of Public Health, 61, doi:10.1007/s00038-015-0691-X

Lovestad, S., Love, J., Vaez, M., \& Krantz, G. (2017). Prevalence of intimate partner violence and its association with symptoms of depression; a cross-sectional study based on a female population sample in Sweden. BMC Public Health, 17(1), 335. doi:10.1186/s12889-017-4222-y

Mokdad, A. H. e. a. (2013). Global burden of diseases, injuries, and risk factors for young people's health during 1990 to 2013: A systematic analysis for the global burden of disease study. The Lancet, 387(10036), 2383-2401. doi:10. 1016/S0140-6736(16)00648-6

Myers, B., Carney, T., Browne, F. A., \& Wechsberg, W. M. (2018). Development of a trauma-informed substance use and sexual risk reduction intervention for young South African women. Patient Preference and Adherence, 12, 1997-2006. doi:10.2147/ppa.S175852

Nduna, M., Jewkes, R. K., Dunkle, K. L., Shai, N. P., \& Colman, I. (2010). Associations between depressive symptoms, sexual behaviour and relationship characteristics: A prospective cohort study of young women and men in the Eastern Cape, South Africa. Journal of The international Aids Society, 13, 44. doi:10.1186/1758-2652-13-44

Price, J. T., Rosenberg, N. E., Vansia, D., Phanga, T., Bhushan, N. L., Maseko, B., .. Pettifor, A. (2018). Predictors of HIV, HIV risk perception, and HIV worry among adolescent girls and young women in Lilongwe, Malawi. JAIDS Journal of Acquired Immune Deficiency Syndromes, 77(1), 53-63. doi:10.1097/qai.0000000000001567

Radloff, L. S. (1977). The CES-D scale a self-report depression scale for research in the general population. Applied Psychological Measurement, 1, doi:10.1177/014662167700100306

Rosenberg, N. E., Bhushan, N. L., Vansia, D., Phanga, T., Maseko, B., Nthani, T., ... Pettifor, A. E. (2018). Comparing youth-friendly health services to the standard of care through "girl power-Malawi": A quasi-experimental cohort study. Journal of Acquired Immune Deficiency Syndromes, 79(4), 458-466. doi:10.1097/qai.0000000000001830

Rosenberg, N. E., Pettifor, A. E., Myers, L., Phanga, T., Marcus, R., Bhushan, N. L., ... Bekker, L.-G. (2017). Comparing four service delivery models for adolescent girls and young women through the 'girl power' study: Protocol for a multisite quasi-experimental cohort study. BMJ Open, 7:e018480. doi: 10.1136/bmjopen-2017-018480

Sikkema, K. J., Choi, K. W., Robertson, C., Knettel, B. A., Ciya, N., Knippler, E. T., .. Joska, J. A. (2018). Development of a coping intervention to improve traumatic stress and HIV care engagement among South African women with sexual trauma histories. Evaluation and Program Planning, 68, 148-156. doi:10.1016/j.evalprogplan.2018.02.007

Tazeen Saeed, A., Aamir, A., \& Fazal, A. (2014). Associations of controlling behaviour, physical and sexual violence with health symptoms. Journal of Women's Health Care, 3(2167-0420), 1-6.

Tsai, A. C. (2013). Intimate partner violence and population mental health: Why poverty and gender inequities matter. PLoS Medicine, 10(5), e1001440. doi:10.1371/journal.pmed.1001440 
Uthman, O. A., Lawoko, S., \& Moradi, T. (2010). Sex disparities in attitudes towards intimate partner violence against women in sub-Saharan Africa: A socio-ecological analysis. BMC Public Health, 10, 223. doi:10.1186/1471-2458-10223

Volpe, E. M., Hardie, T. L., \& Cerulli, C. (2012). Associations among depressive symptoms, dating violence, and relationship power in urban, adolescent girls. Journal of Obstetric, Gynecologic, and Neonatal Nursing: JOGNN/ NAACOG, 41(4), 506-518.

Vos, T., Allen, C., Arora, M., Barber, R. M., Bhutta, Z. A., Brown, A., ... Murray, C. J. L. (2015). Global, regional, and national incidence, prevalence, and years lived with disability for 310 diseases and injuries, 1990-2015: A systematic analysis for the global burden of disease study 2015. The Lancet, 388(10053), 1545-1602.

White, M. E., \& Satyen, L. (2015). Cross-cultural differences in intimate partner violence and depression: A systematic review. Aggression and Violent Behavior, 24(Suppl. C), 120-130. doi:10.1016/j.avb.2015.05.005

WHO. (2013). Global and regional estimates of violence against women: Prevalence and health effects of intimate partner violence and non-partner sexual violence. Geneva: Author.

Woollett, N., \& Hatcher, A. M. (2016). Mental health, intimate partner violence and HIV. SAMJ: South African Medical Journal, 106, 969-972. 